\author{
Acta Scientifica Naturalis \\ Former Annual of Konstantin Preslavsky University - Chemistry, Physics, Biology, Geography \\ Journal homepage: http://www.shu.bg \\ Received: 30.10 .2016 \\ Accepted: 11.01.2017

\section{Fish Lipids as a Valuable Source of Polyunsaturated Fatty Acids} \\ Albena Merdzhanova ${ }^{1}$, Ivaylo Ivanov ${ }^{2}$, \\ Diana A. Dobreva ${ }^{1}$, Lyubomir Makedonski ${ }^{1}$ \\ ${ }^{I}$ Medical University of Varna, Faculty of Pharmacy, \\ Department of Chemistry, 55 Marin Drinov St., 9000 Varna, \\ e-mail: a.merdzhanova@gmail.com \\ ${ }^{2}$ Konstantin Preslavsky University of Shumen, \\ Faculty of Natural Sciences, \\ Department of Organic Chemistry \&Technology, \\ 115 Universitetska str., 9712 Shumen
}

\begin{abstract}
This article presents information about omega-3 (n-3) and omega-6 (n-6) polyunsaturated fatty acid (PUFA) contents in a broad range of commercially important fish species available on Bulgarian fish markets. The aim is to raise consumers' awareness and encourage them to eat fish. Fish species from the Black Sea coast have relatively high proportion of n-3 PUFAs, of which more than $80 \%$ is by EPA (eicosapentaenoic acid, C 20:5 n-3) and DHA (docosahexaenoic acid, C 22:6 n3). Extensive epidemiological studies show that fish consumption is inversely associated with the incidence of cardiovascular diseases (CVD), stroke and the functioning of the brain. About $0.5 \mathrm{~g}$ of omega-3 (EPA+DHA) a day or two servings of oily fish a week are required to reduce the risk of death from CVD. PUFAs needs should be satisfied not only with food additives but with fish lipids containing food.
\end{abstract}

Key words: omega-3, omega-6, Black Sea fish, health benefits

\title{
Introduction
}

The optimal fatty acid (FA) composition of a diet is an important factor in disease prevention and health promotion. The FAO/WHO [7] conclude that "Adequate amounts of dietary fat are essential for health. In addition to their contribution to meeting energy needs, intake of dietary fat must be sufficient to meet the requirements for essential fatty acids". It is well known that fish lipids are one of the best sources of omega-3 (n-3) long-chain polyunsaturated fatty acids (LCPUFA). Thus, a more frequent consumption of fish is recommended. Fish is traditionally viewed as a key element of a healthy balanced diet. National dietary recommendations, and those relating to the Mediterranean diet, include advice on regular fish consumption. In Bulgaria, this advice is included in Food-based Dietary Guidelines for Adults in Bulgaria [8]. Fish consumption in different countries varies widely with Japan, Sweden, Norway and Denmark (55-85 g daily) having the highest, moderate in Greece, France, Great Britain (30-25 g/day) and low (below $20 \mathrm{~g}$ daily) in Romania, Hungary and many others. The negative trend in recent 2-3 decades in Bulgaria is towards a decrease in fish consumption from 12-14 g/day 35 years ago to 8-10 g/day nowadays (the recommendation being at least $30 \mathrm{~g} / \mathrm{day}$ ) [17]. We examined the nutritional and health benefits of commercially important fish in Bulgaria as a valuable source of omega PUFAs and present useful information for consumers about these biologically active components in this article.

70

Corresponding author: a.merdzhanova@gmail.com DOI: 10.1515/asn-2017-0011 
FAs belong to the class of simple lipids, composed of a hydrocarbon chain with a methyl group and a terminal carboxyl group. They are categorized into three classes: saturated fatty acids (SFA), monounsaturated fatty acids (MUFA), and polyunsaturated fatty acids (PUFA) [24]. There are two main families of PUFA: $n-3$ and omega- $6(n-6)$. These FAs are not convertible and have very different biochemical roles in the human body. Linoleic acid (18:2n-6, LA) and alpha-linolenic acid (18:3n-3, ALA) are known as dietary essential FAs (EFA) because they prevent deficiency symptoms and cannot be synthesized by the human body. The family of long chain n-3PUFA comprises eicosapentaenoic acid (EPA), docosapentaenoic acid (DPA) and docosahexaenoic acid (DHA), which are all derived from the parent fatty acid - ALA. While the ratios of these FAs vary as per the food source, DPA is typically less prevalent than EPA and DHA. The family of long chain n-6 PUFA comprises Gama-linolenic acid (18:3n-6, GLA) and arachidonic acid (20:4n-6, ARA), which are derived from the parent fatty acid LA $[6,12,20]$.

The n-6 PUFA deficiency symptoms are dermatitis, growth retardation and infertility in relation to its biological function: LA is a structural component of the skin ceramides, acting as a water barrier; ARA is a precursor of eicosanoids. N-3 deficiency is responsible for insulin resistance and metabolic syndrome, brain metabolic abnormalities, liver steatosis and non-alcoholic fatty liver disease [23]. Furthermore, deficiency of n-3 PUFA leads to a loss of DHA in the brain and retina-rod outer segment phospholipids with a compensatory replacement by $22: 5 \mathrm{n}-6$. This minor change in the membrane phospholipid structure is sufficient to lead to memory loss, learning disabilities and impaired visual acuity [20]. The n-3 FA can partially substitute the n-6 FAs thus alleviating some of the EFA deficiency symptoms. Some of the proven beneficial biological functions of dietary n-3 PUFAs in the organism are related to the provision of energy and carbon atoms; the capability to reduce the amount of serum lipids, EPA as a precursor for " $n-3$ eicosanoids" which directly influences the vascular physiology and the vascular system; the specific role of DHA in the membrane function, especially in the retina and the neuronal tissues. The quantitative ratio between both series must be taken into consideration for an appropriate physiological balance [23]. This FA ratio is important because $n-3$ cannot be converted to an n-6 PUFA in humans, the n- 3 content influences the n- 6 concentration and vice-versa. Therefore, the human capacity to synthesize the DHA can be inhibited by a high intake of n-6 LA. The balance between n-6 and n-3 PUFA in a diet is essential for the homeostasis, the normal growth and the development, because the eicosanoid metabolic products from n- 6 and n-3 FAs exhibit opposing biological properties [6, 20, 23]. Most scientific studies on n-3 PUFAs in recent years aim at determining their immunological and anti-inflammatory effects, especially in cases of asthma, rheumatic arthritis and autoimmune diseases [20, 23, 24]. A lot of studies report on the health benefits of n-3 PUFA intake in relation to cardio vascular disease (CVD) risk factors [12, 14]. Several possible mechanisms by which n-3 PUFAs (as fish lipids) would lead to a reduced CVD risk are established: decrease of triglyceride levels, slowed down metabolism of n-6 PUFA eicosanoids and inhibition of processes of inflammation or related to the increase in HDL cholesterol levels [4]. In a meta-analysis of prospective cohort studies, He et al. [10] estimate that eating fish once a week is associated with a $15 \%$ lower risk of coronary death compared to a fish intake of less than once a month. Each $20-\mathrm{g} / \mathrm{d}$ increase in fish consumption is related to a $7 \%$ lower risk of CHD mortality. The marine-derived LCFA n-3 PUFA EPA and DHA are assumed to be primarily responsible for these health effects. The basic mechanism by which n-3 FA may reduce the risk of CVD is by EPA and DHA levels increase in the phospholipid membranes. Mozaffarian and Rimm [16] combine data from prospective cohort studies to estimate that a reduction of CVD mortality may be achieved with relatively low intakes of EPA and DHA. Modest consumption of fish (1-2 servings/wk, which is $100-200 \mathrm{~g}$ fish/wk) is associated with a $36 \%$ lower risk of coronary death.

\section{Dietary recommendations for omega-3 and omega-6 PUFA}

71 
Several world health agencies and professional organizations as the American Heart Association [1], the European Food Safety Authority [5], and FAO/WHO [7] have issued recommendations to increase the intake of n-3 FAs. These recommendations are based on strong evidence derived by a variety of scientific approaches that link dietary deficiency of LC n-3 FAs with the risk of cardiovascular diseases. They suggest that for the general population an EPA+DHA intake of $250 \mathrm{mg} /$ day (1 serving of fatty fish/week) is sufficient. Others recommend an intake of $\sim 500 \mathrm{mg} /$ day $[2,4,6,12]$. Most studies mainly focus on fish consumption as the main source of EPA and DHA $[10,14,16]$. Some of the global recommendations for LC n-3 PUFAs (EPA+DHA) are made by the International Society for the Study of Fatty Acids and Lipids (ISSFAL) which advocates $500 \mathrm{mg} /$ day [11]. According to the Food Based Dietary Guidelines for Adults in Bulgaria (2006) fish consumption is particularly recommendable, because in Bulgaria the consumption of fish is very low (4.5 $\mathrm{kg}$ annual per capita) compared to the average European levels ( $23 \mathrm{~kg}$ annual per capita) and people have a relatively low intake of n-3 PUFA [8].

\section{Fish as sources of omega-3 and omega-6 PUFA}

The amounts of LCPUFA, most frequently found in fish tissue, range between 8 and 12\% EPA and between 10 to $25 \%$ DHA of the total FA [18, 21, 22, 29].

Freshwater fish contains lower proportions of n-3 PUFAs and higher amounts of n-6 PUFAs than salt water fish. Therefore, the ratio of total n-3 to $n-6$ fatty acids is much lower for freshwater fish than for sea fish, usually ranging from 1 to about 5 . Several studies report that cold-water fish contains higher amounts of n-3 PUFA. Water temperature seems to be an important abiotic factor influencing such amounts $[23,24]$. A comparison between the $n-3$ and $n-6$ PUFA content and the n- $6 / n-3$ FA ratio in commercially important Bulgarian fish species and internationally published data for the same species is shown in Table 1.

Table 1. Omega 3 and omega 6 PUFA content in edible fish tissue ( $\%$ of total FA)

\begin{tabular}{|c|c|c|c|c|}
\hline $\begin{array}{c}\text { Fish } \\
\text { Species }\end{array}$ & $\begin{array}{l}\text { n-3 } \\
\text { PUFA }\end{array}$ & $\begin{array}{l}\text { n- } 6 \\
\text { PUFA }\end{array}$ & $\begin{array}{l}n-6 / \\
n-3\end{array}$ & References \\
\hline $\begin{array}{l}\text { Horse } \\
\text { mackerel }\end{array}$ & $\begin{array}{l}19.40 \% * \\
25.00 \% \\
15.20 \%\end{array}$ & $\begin{array}{l}1.80 \% * \\
2.00 \% \\
2.60 \%\end{array}$ & $\begin{array}{l}0.09 \\
0.08 \\
0.17\end{array}$ & $\begin{array}{l}\text { [Stancheva et al.,2012] } \\
\text { [Ozogul and Ozogul,2007] } \\
\text { [Saglik and Imre,2001] }\end{array}$ \\
\hline Sprat & $\begin{array}{l}19.90 \% * \\
21.70 \% \\
\end{array}$ & $\begin{array}{l}11.90 \% * \\
5.00 \%\end{array}$ & $\begin{array}{l}0.56 \\
0.23 \\
\end{array}$ & $\begin{array}{l}\text { [Stancheva et al.,2012] } \\
\text { [Guner et al., 1999] }\end{array}$ \\
\hline $\begin{array}{l}\text { Black } \\
\text { Sea shad }\end{array}$ & $\begin{array}{l}24.72 \% \\
21.66 \% *\end{array}$ & $\begin{array}{l}2.30 \% \\
5.66 \% *\end{array}$ & $\begin{array}{l}0.09 \\
0.26\end{array}$ & $\begin{array}{l}\text { [Kocatepe and Turan, 2012] } \\
\text { [Stancheva et al, 2011] }\end{array}$ \\
\hline Turbot & $\begin{array}{l}22.70 \% * \\
30.00 \% \\
\end{array}$ & $\begin{array}{l}12.40 \% * \\
2.50 \%\end{array}$ & $\begin{array}{l}0.55 \\
0.08\end{array}$ & $\begin{array}{l}\text { [Merdzhanova et al.,2012] } \\
\text { [Ozogul and Ozogul,2007] }\end{array}$ \\
\hline Garfish & $\begin{array}{l}23.60 \% * \\
18.94 \% \\
\end{array}$ & $\begin{array}{l}7.50 \% * \\
2.41 \%\end{array}$ & $\begin{array}{l}0.32 \\
0.13 \\
\end{array}$ & $\begin{array}{l}\text { [Merdzhanova et al.,2012] } \\
\text { [Kocatepe and Turan, 2012] }\end{array}$ \\
\hline $\begin{array}{l}\text { Rainbow } \\
\text { trout }\end{array}$ & $\begin{array}{l}19.00 \% * \\
15.20 \% \\
\end{array}$ & $\begin{array}{l}22.5 \% * \\
20.60 \% \\
\end{array}$ & $\begin{array}{l}1.18 \\
1.36 \\
\end{array}$ & $\begin{array}{l}\text { [Stancheva et al.,2011] } \\
\text { [Guler and Yildiz, 2011] }\end{array}$ \\
\hline Carp & $\begin{array}{l}4.70 \% * \\
1.90 \%\end{array}$ & $\begin{array}{l}12.90 \% * \\
9.60 \%\end{array}$ & $\begin{array}{l}2.74 \\
5.05\end{array}$ & $\begin{array}{l}\text { [Stancheva et al.,2011] } \\
\text { [Circovic et al., 2011] }\end{array}$ \\
\hline Catfish & $\begin{array}{l}9.83 \% * \\
9.60 \%\end{array}$ & $\begin{array}{l}10.60 \% * \\
7.40 \%\end{array}$ & $\begin{array}{l}1.07 \\
0.78\end{array}$ & $\begin{array}{l}\text { [Stancheva et al.,2014] } \\
\text { [Circovic et al.,2011] }\end{array}$ \\
\hline
\end{tabular}

72

Corresponding author:a.merdzhanova@gmail.com DOI: 10.1515/asn-2017-0011 

significantly higher n-3 values (19.00\%) compared to carp and catfish (4.70-9.83\%). Moreover, an unbalanced $n-6 / n-3$ ratio with a prevalence of $n-6$ PUFAs is highly prothrombotic and proinflammatory, and stimulates the development of atherosclerosis, obesity and diabetes. Due to these facts, a balanced $n-6 / n-3$ ratio $2: 1$ is one of the most important dietary factors in the prevention of obesity, CVD and other chronic diseases. According to some nutritional recommendations $[1,5,7]$, the $n-6 / n-3$ ratio in human diets should not exceed 5.0. All fish species in the present study had an n6/n-3 ratio within the recommended range.

The FA composition of fish lipids varies significantly, especially when compared to vegetable oils and is regulated by the diet, location, season and physiological conditions such as age and sex of the species, which explains the differences observed between fish species n-3 PUFA values. The provision of ALA, EPA and DHA through fish lipids in Bulgaria was among the lowest in the world, which is consistent with the low ALA and DHA levels established in adipose tissue of patients with CVD. An international epidemiological investigation in 2011 [28] finds that forty-seven countries (including Bulgaria as a participant) have almost no access to n-3 PUFAs. The estimated fish intake in Bulgaria (57 g/week) corresponds to an average intake of less than one portion per month. This amount is consistent with our findings about Bulgaria having the lowest ALA and DHA human adipose tissue levels compared to Finland, Germany, Netherlands, Norway, Spain, and the UK. The average adipose tissue ALA in Bulgaria is comparable to the levels found among those with the highest risk of myocardial infarction in Costa Rica. Not surprisingly, regions with the lowest CVD mortality (North America, Europe and Oceania) have high n-3 availability, whereas in Bulgaria, the country with the smallest reduction in CVD mortality, the n-3PUFA intake is not increased [28]. By combining a lower intake of n-6 PUFAs with a higher intake of n-3 PUFAs e.g. through the consumption of Black Sea or freshwater fish species, a relatively significant effect may be achieved.

\section{Conclusion}

Omega-3 FAs as constituents of fish and seafood are the only food source of the long chain fatty acids (EPA and DHA) for humans. Scientific information on FA composition of traditionally consumed fish in Bulgaria is scarce. This study provides recent information on n-3 and n-6 PUFAs content of fish species, well-known in Bulgaria. Based on the current data we can conclude that Black Sea fish species are a very good source of n-3 PUFA (ranging from $19.40 \%$ to $23.60 \%$ of total FA). Freshwater rainbow trout shows significantly higher $\mathrm{n}-3$ values (19\% of total FA) compared to carp and catfish. All fish species in this study have the optimal n-6/n-3 ratio within the recommended range. A balanced diet where fish is consumed at least twice weekly can supply the daily needs of n-3 PUFA in our country. An increased consumption of fish could lead to a reduction of the occurrence and the degree of severity of chronic diseases.

\section{References}

[1]. FAO/WHO. Food and Nutrition, 91, 2010, www. fao.org/docrep/013/i1953e/i1953e00.pdf.

[2] Food Based Dietary Guidelines for Adults in Bulgaria, Ministry of Health National Centre of Public Health Protection With the support of WHO Regional Office for Europe Sofia. 2006, 1-41, http://ncpha.government.bg/files/hranene-en.pdf.

[3] NAFA, National Strategic Plan for Fisheries and Aquaculture 2007-2013. Ministry of Agriculture and Forestry, National Agency for Fisheries and Aquaculture. Sofia. 2007, http://www.mzgar.government.bg/mz_eng/default.asp

[4] Soccol, M.; Oetterer, M., Seafood as Functional Food. - Brazilian Archives of Biology and Technology, 2003, 46, 443-454.

73

Corresponding author: a.merdzhanova@gmail.com DOI: 10.1515/asn-2017-0011 
[5] Erkkilä, A. T.; Schwab, U. S.; de Mello, V. D., Effects of fatty and lean fish intake on blood pressure in subjects with coronary heart disease using multiple medications. European Journal of Nutrition, 2008, 47,319-28.

[6] Kris-Etherton, P.; Harris, W.; Appel, L.; Fish Consumption, Fish Oil, Omega-3 Fatty Acids, and Cardiovascular Disease. Arterioscler Thromb Vasc Biol, 2003, 23, 20-30 http://www.atvbaha.org

[7] Ruxton, C. The benefits of fish consumption, British Nutrition Foundation. Nutrition Bulletin, 2011, 36, 6-19.

[8] Simopoulos, A. P. The importance of the omega-6/omega-3 Fatty Acid ratio in cardiovascular disease and other chronic diseases. Exp. Biol. Med. (Maywood), 2008, 233, 674-688.

[9] Marik, P. E.; Varon, J., Omega-3 dietary supplements and the risk of cardiovascular events: a systematic review. Clinical Cardiology, 2009, 32,365-72.

[10] Colquhoun, D.; Ferreira-Jardim, A.; Udell, T.; Eden, B., Fish, fish oils, n-3 polyunsaturated fatty acids and cardiovascular health. National Heart Foundation of Australia, ABN 98008419 761, 2008.

[11] He, K.; Song, Y.; Daviglus, M. L.; Liu, K.; Van Horn, L.; Dyer, A. R.; Greenland, P., Accumulated evidence on fish consumption and coronary heart disease mortality: a meta-analysis of cohort studies. Circulation, 2004, 109, 2705-2711.

[12] Mozaffarian, D.; Rimm, E. B., Fish intake, contaminants, and human health: evaluating the risks and the benefits. - JAMA, 2006, 296, 1885-1899.

[13] American Heart Association. Heart Attack and Related Diseases, Washington, D. C., 2004, http://www.americanheart.org/

[14] EFSA, Panel on Dietetic Products, Nutrition, and Allergies (NDA); Scientific Opinion on Dietary Reference Values for fats, including saturated fatty acids, polyunsaturated fatty acids, monounsaturated fatty acids, trans fatty acids, and cholesterol. EFSA Journal, 2010, 8, 1461, http://www.efsa.europa.eu.

[15] Calvani M.; Alessandri, C.; Sopo, S. M., Consumption of fish, butter and margarine during pregnancy and development of allergic sensitizations in the offspring: role of maternal atopy. Pediatric Allergy \& Immunology 2006, 17, 94-102.

[16] ISSFAL, International Society for the Study of Fatty Acids and Lipids. Recommendations for Dietary Intake of Polyunsaturated Fatty Acids in Healthy Adults, June 2004.

[17] Özogul, Y.; Özogul, F., Fatty acid profiles and fat content of commercially important seawater and freshwater fish species of Turkey: A comparative study. Food Chemistry, 2007, 100, 1634-1638.

[18] Saglik, S.; Imre, S., Omega3-Fatty Acids in some fish species from Turkey J. of Food Science, 2001, 66, 210-212.

[18] Shahidi, F. Bailey's industrial oil \& fats products. 6th ed., John Wiley \& Sons, 2005.

[19] Stancheva, M.; Galunska, B.; Dobreva, D. A.; Merdzhanova; A., Retinol, Alphatocopherol and Fatty Acid Contents in Bulgarian Black Sea Fish Species, International Journal of Fats and Oils, 2012, 63, 152-157.

[20] Guner, S.; Dincer, B.; Alemdag, N.; Colak, A.; Tufekci, M.; Proximate composition and selected mineral content of commercially important fish species from the Black Sea. J Sci. Food Agric. 1998, $78,337-342$.

[21] Guler, M.; Yildiz, M., Effects of dietary fish oil replacement by cottonseed oil on growth performance and fatty acid composition of rainbow trout (Oncorhynchus mykiss). Turk. J. Vet. Anim. Sci., 2011, 35, 157-167.

[22] Kocatepe, D.; Turan, H., Proximate and Fatty Acid Composition of Some Commercially Important Fish Species from the Sinop Region of the Black Sea. Lipids, 2012, 47, 635-641

[23] Merdzhanova, A.; Stancheva, M.; Makedonski, L., Fatty acid composition of Bulgarian Black Sea fish species. Ovidius University Annals of Chemistry, 2012, 23, 41-47.

[24] Stancheva, M.; Merdzhanova, A.; Makedonski, L., Fatty Acid Composition of Fish species from the Bulgarian Black Sea. Acta Medica Bulgarica, 2011, 1, 26-33,

[25] Stancheva, M.; Merdzhanova, A., Fatty acid composition of common carp, rainbow trout and grey mullet fish species. Agriculture Science and Technology, 2011, 3, 285-289.

74

Corresponding author: a.merdzhanova@gmail.com DOI: $10.1515 /$ asn-2017-0011 
[26] Stancheva, M.; Merdzhanova, A.; Dobreva, D.; Makedonski, L., Common carp (Cyprinus caprio) and European catfish (Sillurus glanis) from the Danube River as sources of fat soluble vitamins and fatty acids. Czech J. Food Sci., $\quad$ 2014, $\quad 32, \quad 16-24$. http://www.agriculturejournals.cz/publicFiles/113975.pdf

[27] Cirkovic, M.; Ljuboevic, D.; Dobrevic, V.; Novakov, N.; Petronievic, R., Chemical composition of body including fatty acids of four cyprinidis fish species cultured at the same conditions. Archiva Zootechnica, 2012, 15, 37-50.

[28] Petrova, S.; Dimitrov, P.; Willett, W.C.; Campos, H.; The global availability of n-3 fatty acids. Public Health Nutrition, 2011, 14, 1157-1164. 